\title{
Ventilation and arterial oxygenation during thoracic surgery
}

\author{
DAVID HATCH ${ }^{1}$ \\ From the Department of Anaesthesia, Charing Cross Hospital, and Milford Chest Hospital, Surrey
}

Considerable interest has been shown in recent years in the relative distributions of alveolar blood and gas flows under various conditions. During thoracic surgical procedures in the lateral position, with one hemithorax open and with controlled ventilation of the lungs, a severe degree of maldistribution of blood and gas may be expected. The upper lung may be freely expanded, retracted by the surgeon, or deliberately deflated by the anaesthetist.

The purpose of this study is to confirm changes in the distribution of inspired gas at various stages of intrathoracic operations and to observe the effects, if any, these changes have on the composition of the arterial blood.

\section{METHODS}

Studies were performed on 22 adult patients undergoing intrathoracic non-cardiac operations (Table I).

\section{T A B LE I}

PATIENTS ACCORDING TO OPERATION GROUP

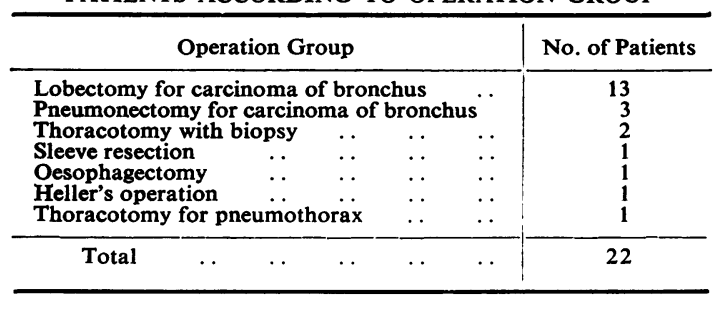

Anaesthesia was induced with $2 \cdot 5 \%$ thiopentone (150 to $500 \mathrm{mg}$.) and suxamethonium (50 to $100 \mathrm{mg}$.). A Bryce-Smith double-lumen, endobronchial tube was passed (Edwards and Hatch, 1965), and paralysis was maintained with D-tubocurarine, the patient remaining supine. A Wright's anemometer was connected to each lumen of the endobronchial tube to record the expiratory minute volume from each lung. The total minute volume was preset by use of the Cape-Waine anaesthetic ventilator, and intermittent positive-

'Present address: Hospital for Sick Children, Great Ormond Street, London, W.C.1 negative pressure ventilation was begun. Ventilator pressure varied from $-5 \mathrm{~cm}$. $\mathrm{H}_{2} \mathrm{O}$ to $+30 \mathrm{~cm} . \mathrm{H}_{2} \mathrm{O}$. Anaesthesia was maintained with $\mathrm{N}_{2} \mathrm{O}+\mathrm{O}_{2}$, supplemented where necessary by minimal halothane $(0.5$ to $1.0 \%)$. In 18 patients the inspired oxygen concentration was kept at $50 \%$. In the remaining four patients it was $25 \%$. An indwelling arterial cannula was inserted into the brachial or radial artery.

When a steady state was reached, synchronous readings were taken from each anemometer, and an arterial sample was also taken. From this latter, oxygen tension was estimated with a Clark-type oxygen electrode (Clark, 1959) and carbon dioxide tension by Astrup's method of intrapolation from the $p H$ (Astrup, Jørgensen, Andersen and Engel, 1960). Readings were repeated with the patient in the lateral position, immediately after the upper hemithorax had been opened, and again with lung retractors in place. All other conditions remained unaltered. The exposed lung was then collapsed and arterial samples were taken at intervals up to 90 minutes. Pre-operative and post-operative arterial samples were also taken.

\section{RESULTS}

Table II shows the results of spirometry, arterial oxygen and carbon dioxide tension, and $p \mathrm{H}$ measurements in the 22 patients studied. Deliberate hyperventilation maintained low carbon dioxide levels throughout. The spirometry results are expressed graphically in Figure 1 . These results confirm the findings of previous authors that in the lateral position the upper lung is preferentially ventilated if not retracted. Figure 2 expresses the arterial blood oxygen tension at various stages of operation. It can be seen that there is a wide standard deviation but no significant difference between samples taken with the patient supine or lateral, with the upper hemithorax open, or with the upper lung partially retracted. The result of a typical individual case is shown in Figure 3. This indicates that acute atelectasis of the upper lung is associated with a drop in arterial oxygen tension, which 
T A B L E I I

FINDINGS IN 22 PATIENTS

\begin{tabular}{|c|c|c|c|c|c|c|c|}
\hline & Pre-operative & Supine & Lateral & Chest Open & Retractors & $\begin{array}{l}\text { One Lung } \\
\text { Collapsed }\end{array}$ & Post-operative \\
\hline$p \mathbf{H}$ & $7 \cdot 39 \pm 0.02$ & $7 \cdot 44 \pm 0 \cdot 15$ & $7 \cdot 44 \pm 0 \cdot 13$ & $7 \cdot 45 \pm 0.18$ & $7 \cdot 44 \pm 0 \cdot 14$ & $7 \cdot 39 \pm 0 \cdot 18$ & $7 \cdot 40 \pm 0.22$ \\
\hline $\mathrm{PCO}_{2}(\mathrm{~mm} . \mathrm{Hg})$ & & & & & & & \\
\hline $\begin{array}{c}\mathrm{Po}_{2}(\mathrm{~mm} . \mathrm{Hg}) \\
\text { (Inspired } \\
\text { concentration }=50 \%)\end{array}$ & $85 \cdot 7 \pm 25 \cdot 2$ & $125 \cdot 9 \pm 45 \cdot 8$ & $146 \pm 23 \cdot 4$ & $165 \pm 57 \cdot 8$ & $114 \pm 60 \cdot 8$ & $81 \cdot 8 \pm 36 \cdot 2$ & $71 \cdot 0 \pm 23 \cdot 2$ \\
\hline $\begin{array}{c}\mathrm{Po}_{2}(\mathrm{~mm} . \mathrm{Hg}) \\
\text { (Inspired } \\
\text { concentration }=25 \%)\end{array}$ & $92 \cdot 8 \pm 28 \cdot 3$ & $117 \cdot 2 \pm 12 \cdot 5$ & $121 \pm 46 \cdot 5$ & $115 \pm 46 \cdot 8$ & $107 \pm 61 \cdot 6$ & $49 \cdot 3 \pm 7 \cdot 21$ & $64 \cdot 1 \pm 23 \cdot 6$ \\
\hline $\begin{array}{l}\text { Spirometry (l./min.) } \\
\text { Right thoracotomy } \\
\text { Upper lung } \\
\text { Lower lung }\end{array}$ & & $\begin{array}{l}6 \cdot 12 \pm 1 \cdot 08 \\
5 \cdot 91 \pm 1 \cdot 07\end{array}$ & $\begin{array}{l}7 \cdot 16 \pm 1 \cdot 42 \\
5 \cdot 16 \pm 1 \cdot 40\end{array}$ & $\begin{array}{l}7 \cdot 67 \pm 1 \cdot 30 \\
4 \cdot 47 \pm 1 \cdot 24\end{array}$ & $\begin{array}{l}5 \cdot 38 \pm 1 \cdot 67 \\
5 \cdot 50 \pm 1 \cdot 26\end{array}$ & $7 \cdot 47 \pm 1 \cdot 17$ & \\
\hline $\begin{array}{l}\text { Left thoracotomy } \\
\text { Upper lung } \\
\text { Lower lung }\end{array}$ & & $\begin{array}{l}6 \cdot 30 \pm 1 \cdot 67 \\
6 \cdot 80 \pm 1 \cdot 90\end{array}$ & $\begin{array}{l}6 \cdot 10 \pm 1 \cdot 90 \\
5 \cdot 70 \pm 1 \cdot 58\end{array}$ & $\begin{array}{l}6.90 \pm 2 \cdot 07 \\
5 \cdot 60 \pm 1 \cdot 60\end{array}$ & $\begin{array}{l}5 \cdot 1 \pm 2 \cdot 40 \\
7 \cdot 10 \pm 1 \cdot 51\end{array}$ & $8 \cdot 10 \pm 1 \cdot 65$ & \\
\hline
\end{tabular}
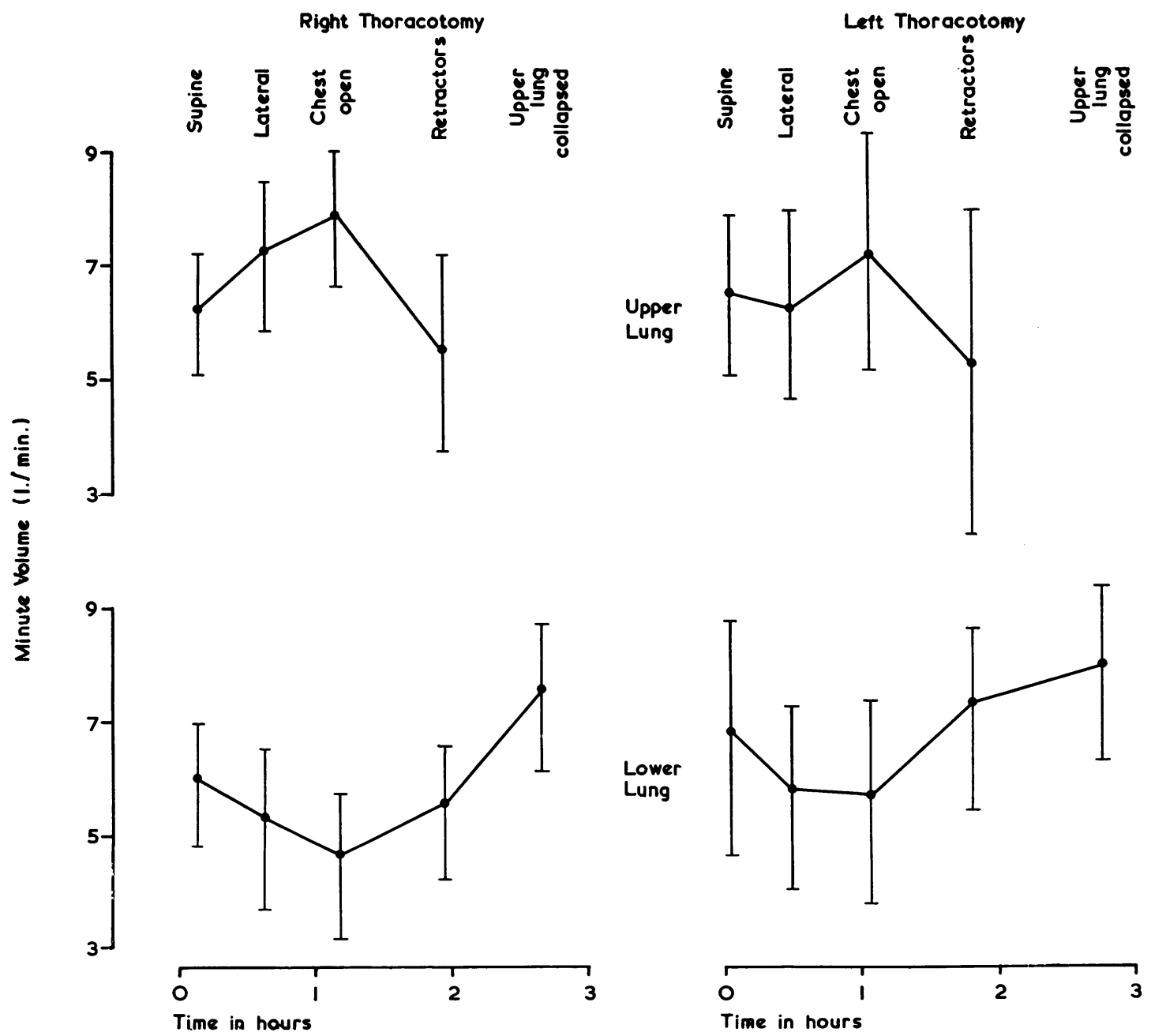

FIG. 1. Changes in expired minute volume at various stages of operation. 


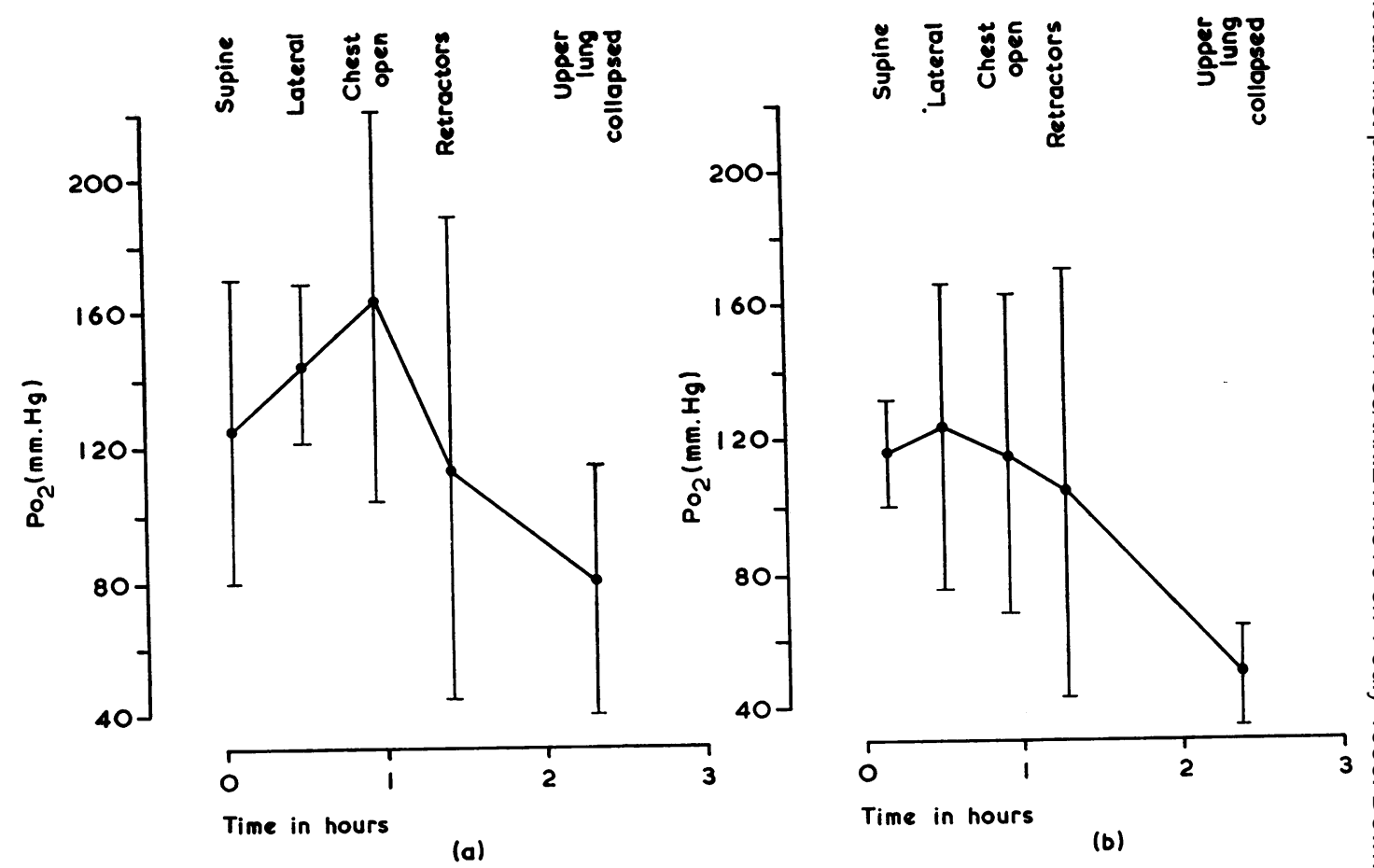

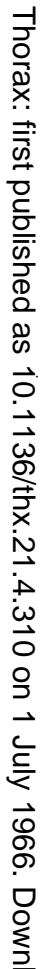

FIG. 2. Changes in arterial oxygen tension at various stages of operation: (a) 18 cases with inspired oxygen concentration of $50 \%$; (b) four cases with inspired oxygen concentration of $25 \%$.

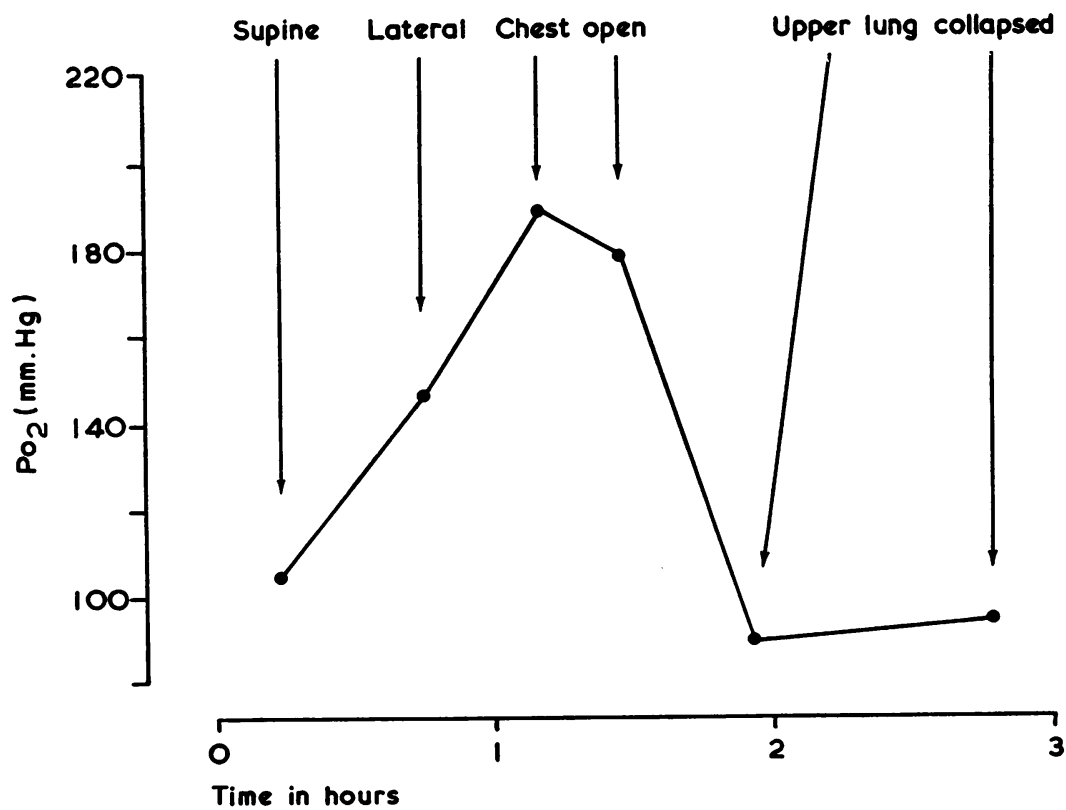

Spirometry:

\begin{tabular}{l|l|l|l|l|} 
Upper lung \\
\cline { 2 - 5 } Lower lung & 6.2 & 7.4 & 7.8 & - \\
\cline { 2 - 5 } & 5.7 & 4.6 & 4.5 & 5.9 \\
\hline
\end{tabular}

(I.Imin.)

FIG. 3. Shows typical changes of arterial oxygen tension and expired minute volume at various stages of operation. 
shows little tendency to rise with time. This drop has been shown to be statistically significant, and it is seen that in the four patients in whom the inspired mixture contained $25 \%$ oxygen, ventilation with one lung produced a mean arterial oxygen tension of only $49 \cdot 3 \mathrm{~mm}$. $\mathrm{Hg}$.

\section{DISCUSSION}

Studies in animals and humans have shown that alterations of regional distribution of ventilation occur in the lateral position, accentuated when the upper hemithorax is opened (Potgieter, 1959; Brownlee and Allbritten, 1956). With intermittent positive pressure respiration during thoracic surgery, the upper lung is better ventilated if not retracted, and Craig, Bromley, and Williams (1962) have shown that 'deaeration' changes may occur in the dependent lung. According to Martin, MacDonald, and Stead (1955) and Nunn (1961), retraction of the exposed lung probably causes a decrease in ventilation of that lung. Studies of regional pulmonary blood flow are complicated to perform but tend to suggest relative overperfusion of the lower lung (Björkman, 1934 ; Rothstein, Landis, and Narodick, 1950 ; Watson, Tyson, Heller, Cincotti, and Gaensler, 1957; Alix and Lozano, 1957). Angiography tends to confirm this (Vaccarezza, Soubrié, Lanari, Molins, and Barousse, 1954).

West (1963) stated that if inspired air and pulmonary blood do not meet in the correct proportions in the lung there is interference with gas exchange, and hypoxaemia results. This occurs when controlled ventilation of the lungs is performed, even in the supine position, and results in increased arterial-alveolar gradients for carbon dioxide and oxygen, but it is not severe enough to cause arterial hypoxia. Campbell, Nunn, and Peckett (1958) suggested that in the lateral position, or with the upper hemithorax open, ventilation:perfusion ratio disturbances may be great enough to affect arterialization. Nunn (1963) stated that ventilation is less important in controlling arterial oxygen tension than inspired oxygen concentration and the distribution of pulmonary blood flow relative to inspired gas. He showed (Nunn, 1961) that maldistribution was present in thoracic surgery, as revealed by increased physiological dead space and the presence of an arterial-end tidal carbon dioxide tension gradient, but he did not at that time have any means of determining the effect of maldistribution on oxygenation of the arterial blood.
In the present series, deliberate hyperventilation was obtained, and there was no difficulty in maintaining low levels of arterial carbon dioxide tension, although Comroe, Forster, DuBois, Briscoe, and Carlsen (1962) stated that with severe maldistribution accumulation of carbon dioxide must occur. Tidal volume was kept constant and could be checked by summing each pair of spirometry readings. Although spirometry confirms the changes in distribution of inspired gas shown by previous authors, there is no significant difference in the mean arterial oxygen tension at any stage of the operation at which both lungs are being ventilated.

The effect of acute atelectasis of one lung on the arterial oxygenation is still a subject of some controversy (Camishion, Ota, Cuddy, and Gibbon, 1961). Although Björk and Salen (1950) showed a considerable shunt through the unaerated lung for at least one hour, Hunter (1958) and Newman, Finer, and Downs (1961) more recently have suggested that any shunt is negligible. Camishion found by direct measurement in dogs that the flow of blood through the pul. monary artery to an acutely collapsed lung did not significantly decrease in the first hour but diminished slowly in the subsequent two hours. Little work has been reported in this field on humans, but Newman studied four patients for up to two and a half hours after acute atelectasis. He did not state what inspired oxygen concentration these patients received but found the oxygen saturation to be satisfactory in three out of the four subjects. Oxygen saturation is not as sensitive as tension because of the shape of the oxygen-haemoglobin dissociation curve. In two of Newman's three 'satisfactory' cases saturations of around $90 \%$ were obtained, and one cannot necessarily agree with his conclusions that the shunt created by controlled atelectasis of the operative lung is not physiologically significant in his cases. More recently, Woodson, Raab, and Ferguson (1963) have shown a 37\% decrease in perfusion after acute atelectasis.

Despite the wide standard deviation in the results of the oxygen tensions in this series, which may be due to the fact that the estimations were carried out on diseased lungs, there is a significant fall in the mean arterial oxygen tension when the upper lung is collapsed. In the four patients in whom the inspired oxygen concentration was only $25 \%$, the mean oxygen tension of the arterial blood fell to an undesirably low level. There was no significant alteration in the $p \mathrm{H}$ or the arterial carbon dioxide tension when the lung was 
collapsed, and the oxygen tension did not show any significant rise with time, up to 100 minutes.

Post-operative hypoxaemia is well recognized after thoracic surgery and was present for up to 14 days post-operatively in this series. It should be noted, however, that as the arterial carbon dioxide tension was not raised during this time, this is not due to underventilation.

\section{SUMMARY}

Studies of the distribution of inspired gas and arterial blood-gas tension have been made at various stages of thoracic surgical procedures in 22 patients. The results of these studies are discussed in relation to ventilation:perfusion ratios and to acute atelectasis of one lung.

I am deeply indebted to Mr. M. Meredith Brown, Dr. E. Mendus Edwards, Dr. G. L. Way, and Dr. G. M. Little for allowing observations to be taken on patients under their care and for invaluable help and advice. Dr. A. Guz and Dr. M. Noble have given much guidance and criticism. I should also like to thank Dr. H. K. Ashworth for help and encouragement throughout this work.

\section{REFERENCES}

Alix, J., and Lozano, C. (1957). Bronchospirometry in latera decubitus positions and in clinical practice: survey of the ventilatory efficiency. $J$. thorac. Surg., 34, 365.

Astrup. P., Jørgensen, K., Andersen, O. S., and Engel, K. (1960) The acid-base metabolism. A new approach. Lancet, 1, 1035.

Björk, V. O., and Salen, E. F. (1950). The blood flow through an atelectatic lung. J. thorac. Surg., 20, 933.

Björkman, S. (1934). Bronchospirometrie: eine klinische Methode, die Funktion der menschlichen Lungen getrennt und gleichzeitig zu untersuchen. Acta med. scand. Suppl., 56.
Brownlee, W. E., and Allbritten, F. F., Jr. (1956). The significance $\overline{\overline{\vec{S}}}$ of the lung-thorax compliance in ventilation during thoracic surgery. $J$. thorac. Surg., 32, 454.

Camishion, R. C., Ota, Y., Cuddy, V. D., and Gibbon, J. H., Jr. (1961). ত Pulmonary arterial blood flow through an acutely atelectatic lung. Ibid., 42, 599.

Campbell, E. J. M., Nunn, J. F., and Peckett, B. W. (1958). A com- $\mathbb{D}$ parison of artificial ventilation and spontaneous respiration with particular reference to ventilation-bloodflow relationships. O Brit.J. Anaesth., 30, 166.

Clark, L. C. (1959). Electrochemical device for chemical analysis. $\vec{\circ}$ U.S. Patent 2,913,386.

Comroe, J. H., Jr., Forster, R. E., DuBois, A. B., Briscoe, W. A., and \# Carlsen, E. (1962). The Lung, 2nd ed., p. 280. Year Book Med. $\vec{\omega}$ Publ., Chicago.

Craig, J. O. C., Bromley, L. L., and Williams, R. (1962). Thoracotomy $\underset{\vec{\gamma}}{\vec{\gamma}}$ and the contralateral lung. Thorax, 17, 9.

Edwards, E. M., and Hatch, D. J. (1965). Experiences with double- i lumen tubes. Anaesthesia, 20, 461.

Hunter, A. R. (1958). Anaesthesia for conservative lung resection for $A$ cancer. Brit. J. Anaesth., 30, 520.

Martin, F. E., MacDonald, F., and Stead, W. W. (1955). Bronchospirometric studies during thoracic surgery. J. thorac. Surg., 29, 327 .

Newman, R. W., Finer, G. E., and Downs, J. E. (1961). Routine use of the Carlens double-lumen endobronchial catheter. Ibid., 42, 327.

Nunn, J. F. (1961). The distribution of inspired gas during thoracic surgery. Ann. roy. Coll. Surg. Engl., 28, 223.

- (1963). In Thoracic Anaesthesia, 1st ed., p. 196, ed. Mushin, W.W. $\overrightarrow{0}$ Blackwell, Oxford

Potgieter, S. V. (1959). Atelectasis: its evolution during upper urinary tract surgery. Brit. J. Anaesth., 31, 472.

Rothstein, E., Landis, F. B., and Narodick, B. G. (1950). Bronchospirometry in the lateral decubitus position. J. thorac. Surg., 19, 821.

Vaccarezza, R. F., Soubrié, A. J., Lanari, C. F., Molins, M. E., and $\bar{O}$ Barousse, A. P. (1954). Valor comparativo de la broncoespirometría y de la angiopneumonografia en la exploración (D funcional de cada pulmón. An. Cated. Pat. Tuberc. (B. Aires), 16,5 .

Watson, T. R., Jr., Tyson, M. D., Heller, M. L., Cincotti, J. J., and $\overline{\bar{O}}$ Gaensler, E. A. (1957). Bronchospirometry. VIII. Differential function during thoracic surgery. Amer. Rev. Tuberc., 75, 730.

West, J. B. (1963). Blood-flow, ventilation, and gas exchange in the lung. Lancet, 2, 1055.

Woodson, R. D., Raab, D. E., and Ferguson, D. J. (1963). Pulmonary hemodynamics following acute atelectasis. Amer. J. Physiol., 205 53. 